\title{
La potestad sancionadora en el Derecho comparado. Francia (I)
}

\author{
Juan Ramón Fernández Torres ${ }^{1}$
}

Sumario: I. INTRODUCCIÓN. II. EL CONCEPTO, SIGNIFICADO Y EXTENSIÓN DE LA SANCIÓN ADMINISTRATIVA. III. LOS PRINCIPIOS DEL DERECHO ADMINISTRATIVO SANCIONADOR. IV. EL PROCEDIMIENTO SANCIONADOR. LOS DERECHOS DE DEFENSA DEL INCULPADO. V. TIPOS DE MEDIDAS SANCIONATORIAS. VI. EL CONTROL JUDICIAL DE LA POTESTAD SANCIONADORA.

\section{INTRODUCCIÓN}

El Derecho administrativo sancionador francés viene siendo objeto de un continuo proceso de reflexión desde hace al menos 25 años². El Consejo de Estado francés primero, y el Consejo Constitucional francés después, reclaman un robustecimiento de las garantías de los ciudadanos acordes con nítidas exigencias constitucionales como respuesta a la proliferación de disposiciones legales que atribuyen crecientes poderes sancionadores a las Administraciones Públicas y a la ausencia de claridad en la elección por parte del legislador entre sanciones administrativas y sanciones penales en función de la naturaleza de las infracciones y del objeto perseguido en cada caso 3 .

La doctrina, por su parte, durante largos años ha mantenido una postura crítica con el ejercicio de la potestad sancionadora por parte de las Administraciones Públi-

1 Catedrático de Derecho Administrativo. Universidad Complutense de Madrid.

2 Vid. una síntesis del mismo en el estudio monográfico de Rebollo Puig, M.: Las sanciones administrativas en el Derecho francés, en AAVV: Estudios jurídicos en conmemoración del $X$ aniversario de la Facultad de Córdoba, Córdoba, 1991, pp. 427-472; y un balance general, en el número especial sobre Las sanctions administratives. Actualité et perspectivas, AJDA (20 de octubre de 2001), así como en Moderne, F.: La sanction administrative (éléments d'analyse comparative), RFDA(2002)3, pp. 483-495. Es significativo que René Chapus manifieste que "la sanción administrativa está de moda" (vid. Droit administratif général, tomo I, Montchrestien, París, 15. ed., 2001, p. 1172).

3 Resulta reveladora la carta dirigida el 24 de enero de 1992 por la entonces Primera Ministra Edith Cresson al Vicepresidente del Consejo de Estado francés Marceau Long, encargándole la elaboración de lo que luego sería el informe (Rapport public) correspondiente al año 1994 intitulado "Le pouvoir de l'Administration dans le domaine des sanctions". 
cas, toda vez que quiebra el dogma tradicional (no escrito) de su reserva a los Jueces y Tribunales penales. Son expresivas las palabras de Marcel Waline pronunciadas en 1963:

"la práctica de las sanciones administrativas es bastante grave porque contribuye, con las sanciones fiscales, a la creación y al desarrollo... de lo que puede llamarse un pseudo-derecho penal"4.

Resulta reveladora la paradoja denunciada por Franck Moderne sobre el particular:

“el fenómeno se desarrolla constantemente bajo nuestros ojos, si bien es curiosamente ignorado o sobreestimado en la gran mayoría de los tratados y manuales de derecho administrativo, que no lo abordan más que a través del prisma estrecho y deformante de la ejecución de las decisiones administrativas"s.

Lo cierto es que la constitucionalidad misma de las sanciones administrativas es incuestionable hoy por hoy, desde que fuera proclamada por el Consejo Constitucional francés en su Decisión de 28 de julio de 1989, en virtud de la cual

“el principio de separación de poderes, no más que ningún otro principio o regla de valor constitucional, no se opone a que una autoridad administrativa que actúa en el marco de prerrogativas de poder público pueda ejercer un poder sancionador desde el momento en que, por una parte, la sanción susceptible de ser impuesta excluye toda privación de libertad y, por otra, el ejercicio del poder de sancionar está revestido por la Ley de medidas destinadas a salvaguardar los derechos y libertades constitucionalmente garantizados"6.

A partir de esta declaración general, el Consejo Constitucional francés rodea la creación de nuevas figuras sancionadoras de garantías que están inspiradas en el Derecho penal y establece los elementos esenciales de un derecho represivo que se extiende a cualesquiera sanciones que revistan carácter punitivo, con independencia de las autoridades (administrativas o jurisdiccionales) competentes para imponerlas.

4 Vid. Waline, M.: Traité de droit administratif, Sirey, París, 8. ${ }^{\text {a }}$ ed., 1959, p. 512. Dicha postura crítica no ha desaparecido del todo. A juicio de Franck Moderne, la vis expansiva de las sanciones administrativas encuentra “difícilmente sus marcas en un Estado de Derecho" [vid. Le pouvoir de sanctions au confluent du droit interne et des droits européens, RFDA (1997)1, pp. 1-26, en especial p. 1].

Numerosos autores entienden que la legitimidad de la potestad administrativa sancionadora queda a expensas de la posibilidad de que intervengan en la fiscalización de su ejercicio unos Jueces y Tribunales que dispongan de poderes

“que se aproximen lo máximo posible a los del juez penal” [vid. Por todos, Mamontoff, C.: La notion de pleine juridiction au sens de l'article 6 de la Convention europénne des droits de l'homme et ses implications en matière de sanctions administratives, RFDA (1999)5, pp. 1004-1021].

5 Vid. Moderne, F.: Le pouvoir de sanction au confluent du droit interne et des droits européens, cit., p. 1.

6 Decisión n. 89 -260 DC de 28 de julio de 1989 (Ley relativa a la seguridad y a la transparencia de los mercados financieros). Vid. al respecto, en especial, Moderne, F.: Sanctions administratives et justice constitutionnelle. Contribution à l'étude du jus puniendi de l'État dans les démocraties contemporaines, Economica, París, 1993, pp. 122 y ss. 
No por ello la caracterización de las sanciones administrativas pierde relevancia. Todo lo contrario. Su proliferación en el curso de las últimas décadas y la influencia ejercida por el Derecho penal hacen imprescindible deslindar las sanciones administrativas, distinguiéndolas de las restantes formas de actuación administrativa gravosa o desfavorable7, tanto más cuanto que los Jueces y Tribunales se inclinan a favor de una interpretación teleológica de las mismas postulando una concepción amplia que posibilite la aplicación extensiva a los interesados de los derechos de defensa. De ahí se desprenden un conjunto de efectos jurídicos que se examinan más adelante.

\section{EL CONCEPTO, SIGNIFICADO Y EXTENSIÓN DE LA SANCIÓN ADMINISTRATIVA}

Resulta paradójico que el concepto de sanción administrativa no esté plenamente afianzado, cuando es determinante para la aplicación de un concreto régimen jurídico configurado a partir de las aportaciones de la jurisprudencia constitucional y contencioso-administrativa. $Y$ ello pese a las numerosas tentativas doctrinales de definir esta noción ${ }^{8}$.

De acuerdo con la jurisprudencia constitucional, son varios los criterios definidores de las sanciones administrativas. En detalle, se entiende por sanción:

1) una decisión unilateral ${ }^{9}$ adoptada por una autoridad administrativa (estatal, como un ministro o, un prefecto; local, como un alcalde; o una autoridad administrativa independiente) $)^{10}$ en el ejercicio de una prerrogativa de poder público ${ }^{11}$. Consecuentemente, no pueden catalogarse como sanciones administrativas ni las sanciones impuestas por jurisdicciones administrativas, tales como las contravenciones de

7 Vid. unas reflexiones más generales sobre la materia, en Huergo Lora, A.: Las sanciones adminis-

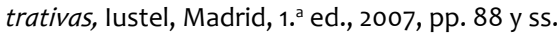

8 Vid. Picard, E.: La notion de police administrative, LGDJ, París, 1984, pp. 327 y ss.; y, más recientemente, Degoffe, M.: Droit de la sanction non pénale, Economica, París, 2000. La doctrina francesa llega a proponer definiciones extensivas de la noción, que incorporan las sanciones impuestas por los Tribunales e, incluso, las sanciones disciplinarias.

9 La jurisprudencia contencioso-administrativa es nítida en este punto: p.e., CE, 9 de octubre de 1996, Association "Ici et maintenant", req. n. 173073 ; CE, 15 de enero de 1997, Societé SERC Fm Radio, req. n. $155049 ;$ y CE, 15 de enero de 1997, Associations Radio - Sud - Vendée - Pictions, req. n. ${ }^{\circ} 177989$. Vid. el análisis de dichos fallos por Moderne, F.: Le pouvoir de sanction au confluent du droit interne et des droits européens, cit., pp. 9 y 10.

10 Vid. al respecto, la jurisprudencia constitucional: por todas, las Decisiones n. ${ }^{\circ}$ 96-373 DC de 9 de abril de 1996 y n. ${ }^{\circ}$ 96-378 DC de 23 de julio de 1996, comentadas por Franck Moderne (vid. Le pouvoir de sanction administrative au confluent du droit interne et des droits européens, cit., pp. 7-9). 0 un organismo de derecho privado que ejerce misiones de servicio público, como el Consejo de las bolsas de valores la llamada Commission des opérations de bourse (Consejo de Estado, Ass., 1 de marzo de 1991, Le Cun), federaciones deportivas u organismos de la seguridad social.

11 Decisión n. ${ }^{\circ} 89-260$ DC de 28 de julio de 1989 (Ley relativa a la seguridad y a la transparencia de los mercados financieros). 
dominio público ("contraventions de grande voirie") 12 y las multas por recurso abusivo, ni las medidas disciplinarias adoptadas en el ámbito profesional por autoridades investidas de funciones jurisdiccionales; y, de forma cumulativa,

2) una decisión administrativa que inflige un mal condenando una conducta ilegal'13. Castiga, pues, un incumplimiento ilegal de una obligación previa, de carácter extracontractual, ya sea legal o reglamentaria ${ }^{14}$. La reacción administrativa conlleva que el comportamiento del autor de la infracción supone una falta, que requiere en todo caso la concurrencia de dolo, culpa o negligencia, esto es, el elemento de la culpabilidad ${ }^{15}$.

Lo que diferencia en este sentido la sanción administrativa de los demás actos administrativos de gravamen o desfavorables es su finalidad represiva ${ }^{16}$. Así y todo, el Derecho francés contempla algunos tipos de medidas administrativas, de carácter punitivo igualmente, que pese a ello disponen de un régimen jurídico singular que determina que no se encuadren entre las sanciones administrativas ${ }^{17}$. Así acontece con:

1) las sanciones contractuales. El establecimiento de un régimen peculiar para las sanciones contractuales obedece al hecho de que responden a un doble fin, la represión de incumplimientos contractuales por un lado, y el aseguramiento del buen funcionamiento de los servicios públicos por otro $^{18}$;

12 Las contravenciones constituyen un tipo de infracciones en materia de dominio público, tipificadas a través de reglamentos, que se integran en el campo del Derecho penal y cuya imposición incumbe a los Tribunales contencioso-administrativos, revistiendo naturaleza esencialmente administrativa, en tanto en cuanto sancionan ilícitos administrativos. Vid. sobre el tema, Chapus, R.; Droit administratif général, tomo I, cit., pp. $792-793$.

13 En palabras de un antiguo presidente del Consejo de Estado durante el período 1966-1976, Raymond Odent,

"el elemento determinante parece ser la voluntad de castigar una falta cometida por aquél a quien la sanción es infligida” [vid. Les droits de la défense, en Études et documents du Conseil d’État(1953)7, p. 55].

De ahí que el Consejo Constitucional francés estime que una norma legal que restringe el ámbito de aplicación de una reducción del impuesto sobre la renta, otorgada a través de pólizas de seguros de vida, no establece una sanción fiscal (Decisión n. ${ }^{\circ}$ 95-369 DC de 28 de diciembre de 1995). Vid. el comentario sobre este punto de Moderne, F.: Le pouvoir de sanction administrative au confluent du droit interne et des droits européens, cit., pp. 3-4.

14 CE, 18 de mayo de 1998, Société Info Première; y 27 de septiembre de 2006, Association Fréquence Mistral.

15 Según Mireille Delmas-Marty y Catherine Teitgen-Colly,

"este criterio finalista, incluso si no es presentado siempre como tal por la jurisprudencia administrativa que se inclina por criterios más diversos en apariencia (móvil, motivo, finalidad...) deriva sin embargo de la misma, ya que a través de estos diversos elementos del acto el juez administrativo en realidad persigue determinar si la medida adoptada se dirige o no a castigar un comportamiento" (vid. Punir sans juger? De la répression administrative au droit administratif pénal, Economica, París, 1. ${ }^{\text {a }}$ ed., 1992, p. 90).

16 Así lo subraya el Consejo Constitucional en su Decisión n. ${ }^{\circ}$ 88-248 DC de 17 de enero de 1989 (Consejo Superior de lo Audiovisual).

17 Vid. desde el punto de vista doctrinal, Mourgeon, J.: La répression administrative, LGDJ, París, 1967, pp. 130 y ss.

18 Según André de Laubadère, Frank Moderne y Pierre Delvolvé,

"las sanciones del contrato administrativo no tienen por objeto sólo reprimir incumplimientos contractuales, sino además garantizar la marcha de los servicios para los que la ejecución de los contratos era útil" (vid. Traité des contrats administratifs, LGDJ, París, 1984, t. II, p. 102). 
2) las sanciones disciplinarias, ya sean de las Administraciones Públicas o ya de los Colegios profesionales. Su aplicación en la esfera doméstica (p.e., los funcionarios públicos) y de acuerdo con reglas concretas vinculadas a la observancia de la deontología profesional justifican su diferenciación con respecto a las sanciones administrativas ${ }^{19}$;

3) las medidas de policía. La finalidad básicamente preventiva en defensa del orden público, la salud o la seguridad pública distingue las medidas de policía de las sanciones administrativas, si bien el límite entre unas y otras no es evidente en todos los casos, como reconoce el propio Consejo de Estado francés a través de su jurisprudencia ${ }^{20}$. Tanto es así que el legislador en ocasiones confiere naturaleza dual a ambas clases de actuaciones administrativa gravosas. La cuestión de la determinación de la naturaleza de las medidas no es ociosa ni mucho menos, prueba de lo cual es la polémica en torno a figuras tales como la suspensión administrativa del permiso de conducir ${ }^{21}$.

A ello se une que las medidas de policía están sujetas a un régimen jurídico distinto del que rige para las sanciones administrativas, lo que es particularmente visible en relación con la aplicación del principio de contradicción. Así, es pacífico que, incluso en ausencia de una disposición específica, el respeto de los derechos de la

El Consejo de Estado francés añade a lo expuesto por aquellos autores que, "además, si las sanciones contractuales del Derecho administrativo son ciertamente diferentes de las sanciones contractuales del Derecho privado, tienen la misma inspiración. Y la existencia del derecho de la Administración de imponer sanciones a sus contratistas jamás ha sido cuestionada por la doctrina" (vid. Conseil d'État, Les pouvoirs de l'Administration dans le domaine des sanctions, cit., p. 37).

19 Vid. en este punto, Corail, J.-L. de: Administration et sanction. Réflexions sur le fondement du pouvoir administratif de répression, en AAVV, Mélanges René Chapus. Droit Administratif, LGDJ París, 1992, pp. 103 y ss.

20 Pueden citarse, entre otras decisiones del Consejo de Estado francés, las siguientes: CE, Sect., 18 de diciembre de 1959, Societé Les Films Lutétia et Syndicat français des producteurs et exportateurs de Films; y CE, Ass., 27 de octubre de 1995, Commune de Morsang-sur-Orge-, Vid. al respecto, Moderne, F.: La sanction administrative (éléments d'analyse comparative), cit., p. 487.

21 En ocasiones la jurisprudencia contencioso-administrativa cataloga genéricamente la suspensión administrativa del permiso de conducir como una sanción administrativa (p.e., CE, 29 de mayo de 1987, Ministre de l'Intérieur et de la décentralisation c/ Guérinel, Rec. p. 188), si bien considera de manera constante que constituye una medida de policía administrativa cuya finalidad es esencialmente preventiva (p.e., CE, Blanquie, Rec. Tables, pag. 429).

Por su parte, la jurisprudencia civil coincide con la del Consejo de Estado, al estimar que la suspensión administrativa del permiso de conducir representa una medida de seguridad provisional, en espera de la decisión judicial.

Ambas construcciones jurisprudenciales son criticadas por la doctrina, para la que la suspensión administrativa del permiso de conducir es percibida como una sanción. El Consejo de Estado francés reconoce que esta medida se configura sin duda como una limitación importante del derecho de conducir, que algunos consideran una pieza capital de la libertad de circulación, pero

"el fundamento de la medida no es tanto la preocupación por sancionar a los conductores peligrosos, que es lo propio de la sanción penal, cuanto la de proteger a la población de los riesgos que se le hace correr"' (vid. Conseil d'État, Les pouvoirs de l'Administration dans le domaine des sanctions, cit., p. 38). 
defensa es una exigencia indeclinable para todas las sanciones administrativas de una determinada gravedad ${ }^{22}$, lo que no ha sido el caso para las medidas de policía al menos hasta la aprobación del Decreto n. ${ }^{\circ} 83-1025$, de 28 de noviembre, relativo a las relaciones entre la Administración y los usuarios ${ }^{23}$. Su artículo 8 impone la regla de la contradicción en el procedimiento que se tramite en todos aquellos supuestos en los que la resolución deba estar motivada en virtud de lo dispuesto en la Ley de 11 de julio de 1979 y, en especial, en relación con las medidas de policía², "salvo urgencia o circunstancias excepcionales y a reserva de las necesidades de orden público"25.

Con todo, hoy día subsisten algunas diferencias entre las sanciones administrativas y las medidas de policía: entre ellas, ciertas garantías jurídicas que sólo son aplicables a las primeras, al igual que la regla de la retroactividad in bonus;

4) lasrevocaciones de autorizaciones(o de consentimiento-retraitd'agrément). En el Derecho Administrativo francés, se identifican tres categorías:

- determinadas revocaciones se configuran como medidas de policía (p.e., las revocaciones de autorizaciones para la explotación de establecimientos o para el ejercicio de actividades) ${ }^{26}$;

- algunas revocaciones contienen elementos represivos (p.e, las revocaciones de autorizaciones motivadas por la inobservancia de las obligaciones ligadas al consentimiento dado); y

- ciertas revocaciones de consentimiento están desprovistas de elementos preventivos o represivos.

Ninguna de las categorías antedichas se cataloga en puridad como una sanción administrativa, si bien la doctrina advierte que no existe una respuesta concluyente, debiendo estarse en todo caso a lo que resulte en cada supuesto específico en función de los motivos esgrimidos por la Administración para ordenar la revocación y de la finalidad perseguida (represiva o no);

22 CE, 17 de enero de 1930, Ribeyrolles, Rec. p. 76; Sect., 5 de mayo de 1944, Trompier-Gavier, Rec. p. 133.

23 La jurisprudencia contencioso-administrativa se mostró tradicionalmente reacia a aplicar el principio de contradicción a las medidas de policía, a falta de una previsión expresa, al estimar que ralentizaba de forma exagerada la toma de decisiones (p.e., CE, 18 de junio de 1975, Dame Cann, Rec. Pg. 362).

24 Entre otros pronunciamientos del Consejo de Estado francés, pueden citarse los que siguen: $C E$, 26 de junio de 1987, FANE, Rec. p. 235, en relación con la disolución de una agrupación; CE, 11 de julio de 1990, Ministre de l'Intérieur c/Mme Mohindée, Rec. p. 212; o CE, 6 de marzo de 1992, SARL Societé.

25 P.e., los fallos del Consejo de Estado francés de 19 de abril de 1991 (Sect.), Demir, Rec. p. 149, y de 13 de junio de 1990, SARL Pub 90, Rec. p. 162.

26 CE, Sect., 22 de marzo de 1996, Société NRJ-SA, req. n. ${ }^{131861 .}$ Vid. un análisis del pronunciamiento en cuestión, en Moderne, F.: Le pouvoir de sanctions administrative au confluent du droit interne et des droits européens, cit., pp. 2 y 3. 
5) las medidas restitutorias. En cuanto se dirigen a reparar el daño infringido a las Administraciones Públicas, difieren de las sanciones administrativas. El problema radica en que las sanciones pecuniarias, y en especial las sanciones de carácter fiscal, persiguen con frecuencia una finalidad doble, represiva y restitutoria, lo que obliga a los jueces y Tribunales a indagar acerca de la misma para determinar su naturaleza. Una jurisprudencia oscilante estima, por ejemplo, que la mayoría de los intereses de demora previstos en la legislación tributaria ostentan naturaleza sancionatoria, de la misma forma que los recargos, no obstante su carácter objetivo ${ }^{27}$.

A pesar de la diferenciación entre las sanciones administrativas y otros tipos de actos administrativos gravosos como los que acaban de citarse, las primeras no han dejado de expandirse, sin un criterio claro, todo sea dicho ${ }^{28}$. A ello contribuyen al menos tres factores. Por un lado, el ámbito de las sanciones administrativas ya no está circunscrito a aquellos supuestos en los que preexiste un vínculo entre el sancionado y la Administración. Durante décadas, las sanciones administrativas eran percibidas como una simple extensión de las sanciones disciplinarias ${ }^{29}$, hasta el punto de que la doctrina en general sostenía que la existencia de un ámbito de aplicación limitado constituía una condición esencial de la legitimidad de las sanciones administrati$\operatorname{vas}^{30}$. El ulterior establecimiento y desarrollo de las sanciones administrativas en ámbitos distintos en los que no existe un vínculo previo voluntario e individualizado entre la Administración y los particulares (p.e., tráfico, regulación de actividades profesionales, etc... ) conduce a la desaparición de esta condición de su existencia, hasta entonces necesaria.

Por otro lado, la expansión del ámbito de aplicación de las sanciones administrativas se produce al compás del surgimiento y desarrollo de las autoridades administrativas independientes (p.e., el Consejo de la Competencia -le Conseil de la Concurrence-, el Consejo superior de lo Audiovisual -le Conseil Supérieur de l'Audiovisuel-, la Comisión de operaciones bursátiles -la Commission des Opérations de Bourse-, etc... ). La atribución a las mismas de poderes de control, vigilancia, inspección y sanción las habilita para imponer sanciones (pecuniarias, de forma primordial), incluso a

27 P.e., el fallo del Consejo de Estado francés de 17 de febrero de 1992, Époux Vermeersch, Rec. p. 62.

28 Vid. Conseil d'État, Les pouvoirs de l'Administration dans le domaine des sanctions, cit., p. 70.

29 Es expresivo que Marcel Waline afirmara en 1937 que "cualquier persona que trabe relaciones con la Administración se sitúa de este modo en la esfera en la que se ejerce su potestad disciplinaria" (nota bajo el pronunciamiento del Consejo de Estado -Sect.- de 15 de mayo de 1936, Belot, D.P. 1937.3.1, apud Conseil d'État, Les pouvoirs de l'Administration dans le domaine des sanctions, cit., p. 43).

30 Jean Marie Auby declaraba en 1952 que las sanciones administrativas "pueden tener su ubicación en un Estado federal, a condición de que su campo de aplicación se halle estrechamente limitado, que no obstaculicen de ninguna manera la represión penal”, condición ésta que era susceptible de verificación a través de la existencia de un nexo individualizado entre la Administración y el interesado" (vid. Les sanctions administratives en matière de circulation, D. 1952, Chron. 25, p. 111, apud. Conseil d'État, Les pouvoirs de l'Administration dans le domaine des sanctions, cit., p. 43). 
terceras personas que no tienen un vínculo previo con la Administración, sin que ello suscite problema alguno de constitucionalidad ${ }^{31}$.

Por último, el pragmatismo también coadyuva a explicar la proliferación de las sanciones administrativas. En concreto, el reforzamiento de la potestad administrativa sancionadora es alentado por una triple preocupación: la descongestión de los Tribunales ordinarios primero, el incremento de la eficacia de la actividad punitiva segundo, y la búsqueda de la adaptación de la sanción tercero ${ }^{32}$.

\section{LOS PRINCIPIOS DEL DERECHO ADMINISTRATIVO SANCIONADOR}

La aplicación de los principios jurídico-penales en el Derecho sancionatorio administrativo es incuestionable. No lo es menos que suscita una polémica doctrinal de envergadura33, que enfrenta a partidarios y detractores de la penalización de las sanciones administrativas, que sin embargo, al decir del Consejo de Estado francés, es aún parcial ${ }^{34}$.

De cualquier forma, los principios jurídico-penales aplicables a las sanciones administrativas son los siguientes ${ }^{35}$ :

1) el principio de legalidad. Se aplica íntegramente a las sanciones administrativas, sin suscitar en la actualidad mayores problemas, tal como resulta de la jurispru-

31 Consejo Constitucional, Decisión n. $89-260$ DC de 28 de julio de 1988, antes mencionada.

32 Vid. Conseil d'État, Les pouvoirs de l'Administration dans le domaine des sanctions, cit., pp. 70 y 71; además, CE, 22 de noviembre de 2000, Société Crédit agricole Indosuez Cheuvreux, Lebon 537.

33 Según la doctrina, ni hay ni puede haber una equivalencia entre las garantías del proceso penal y las del proceso contencioso-administrativo. Como afirma Franck Moderne,con la sanción administrativa "no se trata de asegurar mediante la represión penal el respeto de los valores esenciales de una sociedad, sino de velar por el concreto funcionamiento de un sector o de una actividad" [vid. $L a$ sanction administrative, RFDA (2002)3, pp. 483-495].

Con anterioridad, el mismo autor manifiesta que,

"si bien las garantías procedimentales, en materia de represión administrativa, son de igual naturaleza y alcance que las garantías del procedimiento penal, el recurso a esta forma de represión (por razones de celeridad y eficacia) ya no está justificado. Peor aún, se torna contraproducente porque la multiplicación de las reglas procedimentales inspiradas en el derecho penal no conducirá, de todos modos, al mismo grado de protección que un procedimiento penal probado y puesto en marcha por profesionales de la justicia. En otros términos, la política de despenalización acompañada de medidas procedimentales resueltamente tuitivas de los derechos interesados podría parecerse insidiosamente a una repenalización implícita e imperfecta de la materia. No es seguro que el sistema gane con ello en coherencia y simplicidad" [vid. Moderne, F.: La sanction administrative (éléments d'analyse comparative), cit., p. 495].

34 Vid. Conseil d'État, Les pouvoirs de l'Administration dans le domaine des sanctions, cit., p. 53 y 65 y ss.; asimismo, Dellis, G.: Droit pénal et droit administratif. L'influence du droit pénal sur le droit administratif répressif, LGDJ, París, 1997; y Chapus, R.: Droit administratif général, tomo I, cit., pp. 1176-1178.

35 A la inversa, no son aplicables las reglas de la amnistía a la suspensión de la eficacia, o lo son 14 parcialmente los principios de tipicidad, prescripción y non bis in idem (vid. Dobkine, M., Dalloz, Sirey, 1993, 22e cahier, p. 58; y Chapus, R.: Droit administratif général, tomo I, cit., pp. 1176-1178). 
dencia constitucional y contencioso-administrativa. La única dificultad es la que se origina en la propia incertidumbre acerca del significado mismo del principio de legalidad, en la medida en que las Administraciones Públicas pueden crear algunos tipos de sanciones penales en el ejercicio de su potestad reglamentaria, a tenor de lo dispuesto por el artículo 34 de la Constitución de $1958^{36}$. El Consejo de Estado francés no resuelve la cuestión en términos concluyentes, si bien ofrece algunas pautas en atención a los diferentes supuestos ${ }^{37}$ :

- reconoce, con apoyo en la doctrina del Consejo constitucional francés, que la Administración puede crear nuevas sanciones administrativas (en materia de contravenciones de dominio público, o contraventions de grande voirie, en todo caso), siempre que no sobrepase el tope fijado por la Ley (penal);

- un mero reglamento puede declarar la caducidad de un derecho y la restitución de la ventaja otorgada en caso de la falta de conformidad del autor de una infracción con las condiciones planteadas para la concesión de una ventaja;

- la revocación de autorizaciones o de consentimientos debe estar prevista en normas con rango formal de Leyes, en la medida en que afectan a derechos y obligaciones de carácter civil;

2) el principio de tipicidad. En sintonía con la doctrina, que tradicionalmente ha venido sosteniendo una aplicación flexible del principio de tipicidad en el ámbito administrativo sancionador, el Consejo Constitucional francés suaviza su alcance, afirmando

"que, aplicada fuera del Derecho penal, la exigencia de una definición de las infracciones sancionadas se encuentra satisfecha en materia administrativa por la referencia a las obligaciones a las que el titular de una autorización administrativa está sometido en virtud de las Leyes y reglamentos" 38 .

Esta laxitud, pese a las matizaciones formuladas por el propio Consejo Constitucional francés, por una parte contrasta con el rigor en relación con las sanciones pe-

36 Vid. las lógicas reservas que a propósito del fallo del Consejo de Estado francés de 13 de enero de 1995 (Société Télévision française 1 TF1, Rec. p. 31) formula Franck Moderne, en Le pouvoir de sanction administrative au confluent du droit interne et des droits européens, cit., pp. 10-12.

37 Vid. Conseil d'État, Les pouvoirs de l'Administration dans le domaine des sanctions, cit., p. 56. Según la Sentencia del Consejo de Estado francés de la Sección de 11 de julio de 2008 (Fédération de I'hospitalisation privée, req. n. 300304 ), «cuando la definición de las obligaciones a las que está sometido el ejercicio de una actividad depende del legislador en aplicación del artículo 34 de la Constitución, pertenece sólo a la Ley fijar, llegado el caso, el régimen de las sanciones administrativas que el desconocimiento de estas obligaciones puede aparejar y, en particular, determinar tanto las sanciones contempladas como los elementos constitutivos de las infracciones que estas sanciones tienen por objeto reprimir: la circunstancia según la cual la Ley reenvíe al decreto el encargo de definir sus modalidades o sus condiciones de aplicación no tiene ni por objeto ni por efecto habilitar al poder reglamentario para intervenir en el ámbito de la Ley para definir estos elementos".

38 Decisión n. ${ }^{\circ}$ 88-248 DC de 17 de enero de 1989. 
nales y, por otra, propicia la utilización de enunciados por parte del legislador que no aseguran una completa predeterminación normativa de las infracciones y sanciones, de forma que no existe ni mucho menos el mismo grado de certeza en la definición de los tipos que en el Derecho administrativo sancionador español. En este sentido, debe precisarse que el principio de tipicidad en el Derecho penal francés no tiene en rigor el alcance presumible, como subraya el Consejo de Estado francés ${ }^{39}$;

3) el principio de irretroactividad. De la jurisprudencia constitucional y contencioso-administrativa se infiere la aplicabilidad del principio de irretroactividad a las sanciones administrativas ${ }^{40}$, al igual que el de la aplicación inmediata de la Ley más favorable ${ }^{41}$;

4) el principio de proporcionalidad. La jurisprudencia constitucional defiende la aplicabilidad del principio de proporcionalidad de las penas a las sanciones administrativas ${ }^{42}$, y no sólo a las sanciones fiscales o pecuniarias ${ }^{43}$;

5) la interdicción de las sanciones de plano o automáticas. No obstante la jurisprudencia constitucional ${ }^{44}$, el Consejo de Estado francés considera que

39 Vid. Conseil d'État, Les pouvoirs de l'Administration dans le domaine des sanctions, cit., p. 57.

40 En su Decisión n. ${ }^{\circ}$ 82-155 DC de 30 de diciembre de 1982, el Consejo Constitucional, a propósito de unas sanciones fiscales, declara que

"el principio de irretroactividad así formulado no concierne solamente a las penas infringidas por las jurisdicciones represivas, sino que se extiende necesariamente a toda sanción que revista el carácter de un castigo, incluso si el legislador ha creído que debía reservar su pronunciamiento a una autoridad de naturaleza no judicial" (sic).

Vid. asimismo la jurisprudencia contencioso-administrativa: p.e., CE, 28 de noviembre de 2008, Scea de Caltot, req. N. ${ }^{\circ} 295847$.

41 En su Decisión n. 81-127 DC de 19 y 20 de enero de 1981, el Consejo Constitucional francés otorga valor constitucional a la regla según la cual

"la ley penal debe, cuando establece penas menos severas que su predecesora, aplicarse a las acciones cometidas antes de su entrada en vigor y que no hayan dado lugar a condenas que hayan adquirido fuerza de cosa juzgada" (sic).

Consúltense además los fallos del Consejo de Estado francés de 17 de marzo de 2007, Marcel, Lebon 1.501 y 16 de febrero de 2009, Société ATOM, req. n. ${ }^{2} 274000$, así como Legras, C., Sanctions administratives: rétroactivité in mitius et plein contentieux. Conclusions sur Conseil d'État, ass. 16 février 2009, Société ATOM,

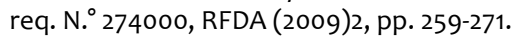

42 Lo hace por vez primera en su Decisión n. ${ }^{\circ}$ 77-237 DC de 30 de diciembre de 1987. Con posterioridad, en su Decisión n. ${ }^{\circ} 88-248$ DC de 17 de enero de 1989, el Consejo Constitucional francés considera que

“el montante de la sanción pecuniaria debe estar en función de la gravedad de los incumplimientos cometidos y en relación con las ventajas obtenidas del incumplimiento por el servicio autorizado" (sic).

43 Decisión del Consejo Constitucional n. ${ }^{\circ}$ 88-248 DC de 17 de enero de 1989, por un lado; y CE, 13 de enero de 1995, Société Télévision française 1 TF1, Rec. p. 32; CE, Sect., 10 de julio de 1995, Société Télévision française 1 TF1; CE, 20 de mayo de 1996, Société Vortex, req. n. ${ }^{\circ} 167694$ y 171.423; CE, 9 de octubre de 1996, Association «lci et maintenant», req. n. 173023 ; y CE, 15 de enero de 1997, Association Radio-Sud-Vendée-Pictons, req. n. ${ }^{177989}$. Vid. al respecto, Moderne, F.: Le pouvoir de sanction administrative au confluent du droit interne et des droits européens, cit., pp. 13-15.

44 Decisiones del Consejo Constitucional n. ${ }^{\circ}$ 87-237 DC de 30 de diciembre de 1987, n. ${ }^{\circ} 88-248$ DC 16 de 17 de enero de 1989 , o n. ${ }^{\circ}$ 97-307 DC de 25 de febrero de 1992. 
"una sanción automática, que castigue una infracción suficientemente precisa y simple en su definición, y de un montante adaptado a la infracción, sería sin duda constitucional. Es, en la medida en que una sanción automática no permitiera respetar el principio de proporcionalidad cuando sería contraria a la Constitución"45;

6) la acumulación de sanciones y el principio non bis in idem. La aplicación del principio non bis in idem está condicionada por el principio de independencia entre las sanciones penales y las administrativas, que las declara compatibles, de suerte que se estiman susceptibles de acumulación respecto de unos mismos hechos ${ }^{46}$. Así lo entiende el Consejo de Estado francés desde antiguo ${ }^{47}$, y lo corrobora el Consejo Constitucional francés, con ciertos límites. En efecto, si en un principio el Consejo Constitucional francés establece tan sólo la exigencia de la observancia en cualquier caso del principio de proporcionalidad ${ }^{48}$, con posterioridad se hace eco de las críticas hacia el sistema de acumulación y proclama el principio de no acumulación de las sanciones administrativas de carácter pecuniario y las sanciones penales, elevándolo a rango constitucional ${ }^{49}$.

Ahora bien, la primacía del principio non bis in idem es incontrovertible en relación con las sanciones administrativas, tanto más cuanto que representa un principio general del Derecho ${ }^{50}$, aunque carezca de rango constitucional. El propio Consejo de Estado francés estima que el establecimiento de medidas accesorias constituye per se un supuesto de acumulación susceptible de transgredir en una hipótesis el principio non bis in idem.

En definitiva, la aplicación de los principios jurídico-penales a las sanciones administrativas no es ni íntegra, ni mimética, sino que admite una diversidad de excepciones, variando en función de los sectores de actividad, correspondiendo un gran protagonismo a los Tribunales contencioso-administrativos en la determinación de su operatividad real51.

45 Vid. Conseil d'État, Les pouvoirs de l'Administration dans le domaine des sanctions, cit., p. 59.

46 Vid. sobre la materia, Chapus, R.: Droit administratif général, tomo I, cit., pp. 1177 y 1178; y Dellis, G.: Droit pénal et droit administratif. L'influence des principes du droit pénal sur le droit administratif répressif, LGDJ/Montchrestien, París, 1998, pp. 248 y ss.

47 Lo ratifican pronunciamientos del Consejo de Estado francés tales como los siguientes: CE, Sect., 19 de febrero de 1943, Grandgirard, Rec. p. 43; 3 de enero de 1945, James, Rec. p. 3; 9 de octubre de 1996, Associations “Ici et maintenant", req. n. 173073 ; y avis 4 de abril de 1997, Jamet, req. n. 183658 . Ahora bien, el propio Consejo de Estado francés propugna la limitación a tres del número máximo de supuestos de exclusión del principio non bis in idem, referidos a las sanciones administrativas de carácter provisional, la distinta naturaleza de las sanciones administrativas y las penales y la excepcionalidad de estas últimas (vid. Conseil d'État, Les pouvoirs de l'Administration dans le domaine des sanctions, cit., pp. 79 y 80.

48 Decisión del Consejo Constitucional n. ${ }^{\circ} 89-260$ DC de 28 de julio de 1989.

49 Decisión n. ${ }^{\circ}$ 96-378 DC de 23 de julio de 1996. A juicio de Frank Moderne, no está claro que este principio constitucional sea susceptible de aplicación extensiva a otros tipos de sanciones administrativas. Vid. Moderne, F.: Le pouvoir de sanctions administrative au confluent du droit interne et des droits européens, cit., pp. 15 y 16.

50 CE, 23 de abril de 1958, Commune du Petit-Quevilly, AJDA, 1958, II, p. 383.

51 Vid. Dellis, G.: Droit pénal et droit administratif. L'influence des principes du droit pénal sur le droit administratif répressif, cit., pp. 17-20; y Corail, J.-L. de: Administration et sanction. Réflexions sur le fondement du pouvoir administratif de répression, cit., pp. 121 y ss. 


\section{EL PROCEDIMIENTO SANCIONADOR. LOS DERECHOS DE DEFENSA DEL INCULPADO}

Los derechos de la defensa se configuran como todo un principio, que reviste carácter fundamental y está dotado de valor constitucional ${ }^{52}$. Dicho principio conlleva la obligación de la observancia de la regla de la contradicción en el procedimiento sancionador. Como señala el Consejo Constitucional,

"ninguna sanción puede ser infligida sin que el titular de la autorización haya tenido ocasión, por igual, tanto de presentar sus observaciones sobre los hechos que se le imputan, como de acceder al expediente que le concierne" ${ }^{53}$.

Más aún, de acuerdo con la jurisprudencia constitucional, el principio de los derechos de defensa

“implica, especialmente en materia penal, la existencia de un procedimiento justo y equitativo que garantice el equilibrio de las partes" ${ }^{54}$.

Dicho esto, la regulación del procedimiento varía en consideración a las peculiaridades que en su caso introduzca la legislación sectorial. En algunos supuestos, se exige que la sanción venga precedida del correspondiente requerimiento (mise en demeure) de conformidad con las obligaciones impuestas 55 ; entre otros, su adopción está supeditada al respeto del derecho de audiencia del inculpado. En cualquiera de estos casos, el procedimiento debe cumplir las exigencias del principio de imparcialidad, considerado como un principio general del derecho ${ }^{56}$.

52 Decisión del Consejo Constitucional n. ${ }^{\circ}$ 76-70 DC de 2 de diciembre de 1976. Vid. Moderne, F.: $L a$ sanction administrative (éléments d'analyse comparative), cit., p. 495; y Ferrari-Breeur, Ch.: La contradiction et le pouvoir de sanction de l'Administration, RFDA (221)1, pp. 33 y ss.

53 Decisión del Consejo Constitucional n. 88-248 DC de 17 de enero de 1989. En el ámbito fiscal, la cuestión ha suscitado opiniones dispares hasta hace no mucho. Mientras que el Consejo Constitucional francés declara procedente la aplicación del principio a las sanciones fiscales (Decisiones n. ${ }^{\circ}$ 89-268 DC de 29 de diciembre de 1989 y n. ${ }^{\circ}$ 90-286 DC de 28 de diciembre de 1990) con apoyo en la legislación, el Consejo de Estado francés sostiene lo contrario, con respaldo en la autonomía del Derecho fiscal (27 de abril de 1979, Rec. p. 169; o 16 de febrero de 1987, requête n. ${ }^{\circ}$ 50422, RJF 1987, n. $\left.{ }^{\circ} 419\right)$.

54 Decisión del Consejo Constitucional n. $89-260$ DC de 28 de julio de 1989 y CE, 27 de octubre de 2006, req. n. ${ }^{\circ} 278069$. El Consejo de Estado francés prescribe otro tanto del procedimiento administrativo sancionador y del proceso contencioso-administrativo, al tiempo que subraya que el primero no se debe equiparar al segundo. Vid. su fallo de 31 de enero de 2007, Compagnie Corsair Internationale SA, y Silva, I. de: Le contrôle des nuisances sonores aéroportuaires: le procédure de sanction. Conclusions sur Conseil d'État, 31 janvier 2007, Compagnie Corsair Internationale SA, RFDA (2007)4, pp. 757-769.

55 René Chapus tilda de desconcertante la previsible consecuencia de la imposibilidad de sancionar el primer incumplimiento (vid. Droit administratif général, tomo I, cit., p. 1174). Vid. los siguientes fallos del Consejo de Estado francés: CE, Ass. 11 de marzo de 1993, SA La Cinq, p. 117; y lo de julio de 1995, Soc. TF1, AJ 1995, p. 637, entre otros.

56 CE, 27 de octubre de 1999, Fédération française de football; y 26 de septiembre de 2008, Assistance publique hopitaux de Paris, req. n. 306922. 


\section{TIPOS DE MEDIDAS SANCIONADORAS}

El contenido de las sanciones administrativas puede variar según su tipología y las autoridades competentes. Pueden consistir bien en multas pecuniarias pura y simplemente, o bien en típicas sanciones de privaciones de derechos otorgados por actos administrativos de cuya titularidad se abusa, tales como las revocaciones de autorizaciones o la interdicción del ejercicio de ciertas profesiones. El Consejo de Estado francés distingue cuatro grandes categorías de sanciones administrativas:

1) las revocaciones de autorizaciones (o de consentimiento). Sin perjuicio de lo expuesto antes, constituyen la categoría más extendida, estando presente en la mayoría de los campos de actividad administrativa, como el laboral y social (p.e., las revocaciones de consentimiento de talleres protegidos, agencias de modelos, organismos recaudadores de fondos de formación profesional, agencias de trabajo temporal, centros de transfusión sanguínea, etc...), los transportes (p.e., la revocación de la autorización de explotación de una empresa de transporte por carretera, la suspensión o revocación de la autorización de utilización de un aeródromo, etc... ), los sectores audiovisual y eléctrico, los seguros, o los mercados financieros y de valores.

Dentro de esta primera categoría tienen entidad propia las prohibiciones del ejercicio de profesiones (p.e., la revocación del consentimiento de arquitecto-rehabilitador, de carga en la vía pública -taxis-, de la tarjeta profesional de agente de la propiedad inmobiliaria, agente artístico, periodista, agente privado de investigación, etc...);

2) las medidas accesorias de obligaciones legales (p.e., las multas a empresas por el incumplimiento de obligaciones establecidas por el ordenamiento jurídico en materia de transporte aéreo, contratación de personal, etc...);

3) las medidas preventivas fundadas en la imperiosa tutela de la seguridad, la salud o la salubridad pública, tales como la suspensión administrativa del permiso de conducir. En estos casos, la Administración dispone generalmente de un amplio margen de apreciación para fijar el plazo de duración de la suspensión; y,

4) las multas pecuniarias. De forma general, y salvando supuestos excepcionales (p.e., el sector de lo audiovisual y, por supuesto, el ámbito tributario), compete a autoridades administrativas independientes que regulan y controlan determinados sectores de actividad (economía y finanzas) la potestad de imponer multas pecuniarias, que pueden llegar a ser de cuantías muy elevadas ${ }^{57}$.

57 Vid. Conseil d'État, Les pouvoirs de l'Administration dans le domaine des sanctions, cit., p. 53. A este respecto, el Consejo Constitucional francés manifiesta sus reservas respecto a la constitucionalidad de las sanciones de carácter automático (Decisiones n. ${ }^{\circ} 88-248$ DC de 17 de enero de 1989 y n. ${ }^{\circ}$ 92-307 DC de 25 de febrero de 1992), a pesar de su frecuente existencia, en particular en el campo tributario, hasta extremos desconocidos en el Derecho español. 
También se cataloga como un tipo más de sanción administrativa la reducción del derecho a la percepción de pagos compensatorios por superficie o incluso la prohibición de su cobro en el ámbito de la ejecución de la Política Agraria Común $(\mathrm{PAC})^{58}$.

Junto a ello, debe retenerse, en línea de continuidad con lo ya expuesto, que, frente al planteamiento del ordenamiento jurídico español, que proclama con énfasis el principio de incompatibilidad y non bis in idem, en el Derecho francés es frecuente la acumulación de sanciones administrativas y penales por unos mismos hechos. En unos casos, las sanciones administrativas revisten carácter provisional (p.e., la suspensión administrativa del permiso de conducir); en otros, constituyen la medida sancionatoria principal, a la que se suman las sanciones penales independientes de las primeras (así acontece en materia fiscal, defensa de la competencia o mercados de valores).

\section{EL CONTROL JUDICIAL DEL EJERCICIO DE LA POTESTAD SANCIONADORA}

La fiscalización judicial de las sanciones administrativas es una cuestión que suscita varias observaciones. En primer lugar, la revisión judicial de las sanciones administrativas no corresponde única y exclusivamente a los Tribunales contencioso-administrativos (al Consejo de Estado francés, tratándose de sanciones impuestas por órganos colegiados). Tanto la jurisprudencia constitucional ${ }^{59}$ como el legislador atribuyen en ocasiones a la jurisdicción ordinaria6 ${ }^{60}$ (el Tribunal de Apelación de París - Cour d'appel de Paris-) la competencia para resolver los litigios originados en las sanciones impuestas por autoridades administrativas independientes (p.e., la Comisión de operaciones de bolsa, el Consejo de la Competencia o el Consejo de las Bolsas de Valores).

En segundo lugar, debe retenerse que la mera interposición del recurso contra una resolución sancionadora no implica la suspensión de su eficacia, a diferencia de lo dispuesto con respecto a la interposición de un recurso de apelación. Cuestión distinta es que, no obstante su excepcionalidad, no esté prevista la posibilidad de la sus-

Por otro lado, respecto de la determinación de la concreta multa pecuniaria, habitualmente la legislación no contiene una escala de las penas y, por el contrario, confiere a la Administración una gran libertad decisoria, dentro del respeto obligado al principio de proporcionalidad (p.e., mediante el establecimiento de topes o cuantías -o porcentajes- máximos, en función de criterios tales como el beneficio ilegalmente obtenido).

58 CE, 28 de noviembre de 2007, Société Ferme de Rumont, req. n. 287553.

59 Decisión del Consejo Constitucional n. ${ }^{\circ} 86-224$ DC de 23 de enero de 1987. En este pronunciamiento, que concierne al Consejo de la Competencia, el Consejo Constitucional francés admite de modo expreso la validez de una transferencia de competencia a favor de los Jueces y Tribunales ordinarios.

60 Tanto es así que algún autor afirma que estos recursos contra sanciones acordadas por autoridades administrativas independientes instituyen ante los Jueces y Tribunales ordinarios "un contencioso anulatorio de actos administrativos, extendido al poder de reforma” (vid. Boutard-Labord, M.C., LPA 1990, n. ${ }^{\circ}$ 50, 7, apud Conseil d'État, Les pouvoirs de l'Administration dans le domaine des sanctions, cit., p. 63). 
pensión judicial de la ejecución del acto recurrido. Cualquiera que sea el Juez o Tribunal competente para pronunciarse sobre la legalidad de la actuación administrativa sancionadora, la normativa procesal de aplicación debe contemplar semejante eventualidad ${ }^{61}$.

En tercer lugar, en cuanto a la extensión de las garantías de los justiciables en sede contencioso-administrativa, depende en rigor del tipo de recurso interpuesto:

1) con carácter general, el recurso por exceso de poder tiene alcance restringido, de manera que a través del mismo el recurrente puede obtener tan sólo un fallo anulatorio de la sanción administrativa que le ha sido impuesta ${ }^{62}$. En relación con el control sobre el fondo de la decisión administrativa, o bien se circunscribe al del error manifiesto de apreciación en la elección de la sanción, o bien constituye un control completo que incluye el de la proporcionalidad entre la infracción y la sanción ${ }^{63}$. De ordinario, el control es limitado cuando el Juez o Tribunal entiende que no puede o no debe sustituir su apreciación por la de la Administración sancionadora, en particular cuando concurren aspectos de simple oportunidad o se trata de una materia esencialmente técnica. A falta de una disposición expresa, la jurisprudencia cataloga habitualmente como recurso por exceso de poder el recurso formulado contra la sanción acordada por una autoridad administrativa ${ }^{64}$;

61 Lo exige sin ir más lejos la jurisprudencia constitucional (Decisión del Consejo Constitucional n. 86-224 DC de 23 de enero de 1987).

62 Vid. acerca de la evolución del sentido y alcance del control jurisdiccional ejercido por los Tribunales contencioso-administrativos a través del recurso por exceso de poder y de las diferencias en función de las clases de sanciones (disciplinarias o profesionales), Guyomar, M.: Le contrôle des sanctions professionelles. Les sanctions infligées par une autorité administrative (Commission nationale des Experts en automobiles), Conclusions sur Conseil d'État, Section, 22 juin 2007, M. Patrick Arfi, RFDA (2007)6, pp. 1199-1210.

63 CE, Ass., 11 de marzo de 1994, Sté La Cinq, Rec. p. 117; y CE, Sect., 22 de junio de 2007, Arfi. Ello es al margen de aquellos supuestos que deben ventilarse ante la jurisdicción penal. Vid. Chapus, R.: Droit du

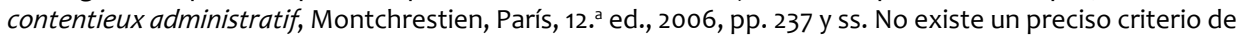
distribución de competencia entre ambos órdenes juridiccionales, como señala la doctrina, por todos, Degoffe, M.: Droit de la sanction non pénale, cit., pp. 347 y ss; y Legras, C.: Sanctions administratives: rétroactivité in mitius et plein contentieux. Conclusions sur Conseil d'État, Ass., 16 février 2009, Société ATOM, req. n. 274000, cit., pp. 267 y 268 en especial. Este último declara que

"el juez del exceso de poder se ha beneficiado de avances que han modificado profundamente las condiciones de su intervención y, por vía de consecuencia, metamorfoseado la distinción de los contenciosos. La frontera entre recurso de plena jurisdicción y recurso por exceso de poder se ha atenuado a medida que se ha afirmado una aproximación concreta y pragmática del oficio del juez del exceso de poder, fruto de evoluciones legislativas y jurisprudenciales que se han situado bajo el signo de la utilidad de su intervención" (sic).

Lo cierto es que de la jurisprudencia contencioso-administrativa emanada del Consejo de Estado francés se desprende que el juez del exceso de poder está investido del poder para señalar de oficio a la Administración el alcance de la anulación y de las consecuencias, incluidas las de carácter transitorio (CE, Ass., 29 de julio de 2001, Vassilikiotis, Lebon 303), así como para ordenar una reforma interpretativa (CE, 25 de marzo de 2002, Caisse d'assurance - incidents agricoles du Bas-Rhin, Lebon 110), modular los efectos de la anulación en el tiempo (CE, 11 de mayo de 2004, $A C$ !, Lebon 197), e, incluso, evitarla cuando no esté justificada (CE, Sect., 6 de febrero de 2004, Hallol, Lebon 48).

64 CE, 5 de abril de 1944, Guignard, Rec. Pg. 110; o 6 de marzo de 1989, Sté de bourse. JFA Buisson, Rec, p. 83. En su pronunciamiento de Asamblea de 1 de marzo de 1991 (Le Cun), el Consejo de Estado 
2) el recurso de plena jurisdicción faculta al Juez o Tribunal para declarar no sólo la invalidez y consiguiente nulidad de la resolución sancionadora, sino además su modificación, en particular cuando impone una multa pecuniaria que estima excesi$v a^{65}$, incluso para imponer por sí sólo la sanción que corresponda ${ }^{66}$. La explicación radica en que en estos supuestos el Juez o Tribunal no se limita a ejercer un control sobre la adecuación de la sanción a la infracción cometida, sino que va más allá, sustituyendo a la Administración ${ }^{67}$ en la fijación de la sanción correspondiente.

La elección entre ambas vías de recurso no es nítida, ni mucho menos, como ha sido apuntado antes. En línea con los postulados del Consejo Constitucional ${ }^{68}$ francés, el Consejo de Estado francés propugna, de forma general, la necesidad del establecimiento de un recurso de plena jurisdicción ${ }^{69}$, "que tiene la ventaja de poner fin al litigio definitivamente", si bien reconoce las ventajas del recurso por exceso de poder en determinados supuestos (p.e., sanciones de escasa cuantía o de especial complejidad).

"De este modo -añade-, la dificultad de la materia se convertiría en un criterio para la elección del tipo de contencioso, y no ya para la intensidad del control del juez del exceso de poder, que sería siempre un control normal de las sanciones pecuniarias" 70 .

francés estima que, si bien el recurso contra las sanciones impuestas por el Consejo de las Bolsas de Valores debe considerarse ante el silencio legal como un recurso por exceso de poder, ejerce un control normal, que comprende incluso un juicio de proporcionalidad. Vid. a este propósito, Guyomar, M.: Le contrôle des sanctions professionelles. Les sanctions infligées par une autorité administrative (Commission nationale des Experts en automobiles. Conclusions sur Conseil d'État, Section, 22 juin 2007, M. Patrick Arfi, cit., pp. 1199-1210.

65 Vid., entre otros fallos del Consejo de Estado, los siguientes: CE, Sect. 5 de abril de 1996; 6 de abril de 1998, Union Synd. de la production audiovisuelle, 15 de marzo de 2006, M. Barre; o 13 de julio de 2006, Dokham.

66 P.e., CE, 11 de marzo de 1994, La Cinq, Lebon 117.

67 O al Consejo Superior Audiovisual (Conseil Supérieur de l'Audiovisue), la Autoridad de los Mercados Financieros (Autorité des marchés financiers), la Comisión Nacional de Control de los Seguros, las Mutuas y los Institutos de Revisión (Commission Nationale de Contrôle des assurances, des mutuelles et des institutions de prévoyance), la Comisión de Regulación de la Energía (Commission de régulation de l'énergie), la Autoridad de Regulación de las Comunicaciones Electrónicas y el Correo (Autorité de régulation des Communications électróniques et des postes), la Comisión Nacional de Informática y Libertades (Commission Nationale de l'informatique et des libertés), la Autoridad de Control de las Molestias Sonoras Aeroportuarias (Autorité de côntrole des nuissances sonores aéroportuaires) o, incluso, el Consejo de la Competencia (Conseil de la concurrence).

68 Decisiones n. ${ }^{\circ} 88-248$ DC de 17 de enero de 1989; y n. ${ }^{\circ}$ 92-307 DC de 25 de febrero de 1992.

69 En este punto, el Consejo de Estado francés coincide con el parecer de la doctrina. Así, G. Dellis estima que

“esta forma de control jurisdiccional (el recurso por exceso de poder) no se adecúa a las particularidades de la sanción administrativa y sólo proporciona una tutela incompleta a los sancionados. De manera más precisa, el recurso por exceso de poder se presenta como un "proceso al acto", de naturaleza, por lo tanto, objetiva, en el que sólo se plantea el problema de su legalidad y no tiene otro resultado posible que la anulación de la decisión impugnada" (vid. Droit pénal et droit administratif. L'influence des principes de droit pénal sur le droit administratif répressif, cit., pp. 391 y ss.).

70 Vid. Conseil d'État, Les pouvoirs de l'Administration dans le domaine des sanctions, cit., p. 65. En opinión de la Maître des requêtes au Conseil d’État y Comisaria del gobierno Claire Legras, 
Con todo, la cuestión dista mucho de estar zanjada en la actualidad, como pone de manifiesto la doctrina jurisprudencial más reciente, que distingue los supuestos en atención a la tipología de las sanciones administrativas objeto de recurso, desde una perspectiva resueltamente casuística y pragmática ${ }^{71}$.

«esta extensión conferida al contencioso de plena jurisdicción nos parece que responde a la reserva que podríais sentir a tener que decidir en calidad de juez de plena jurisdicción tratándose de sanciones pronunciadas en ámbitos sensibles o de un gran tecnicismo. El poder de reforma se ejerce en efecto en los contenciosos más diversos. Por añadidura, la plena jurisdicción se caracteriza por una plasticidad que puede permitir al juez no agotar sus prerrogativas, en particular, no hacer uso de su poder de reforma si estima que las circunstancias concurrentes no se lo permiten" (vid. Sanctions administratives: retroactivité in mitius et plein contentieux. Conclusions sur Conseil d'État, Ass. 16 février 2009, Société ATOM, req. n. ${ }^{\circ} 274999$, cit., p. 265).

Vid. sobre la influencia ejercida por la jurisprudencia del Tribunal Europeo de Derechos Humanos en la ampliación del ámbito de aplicación del recurso de plena jurisdicción y de los poderes de los órganos juzgadores, Mamontoff, C.: La notion de pleine juridiction au sens de l'article 6 de la Convention Européenne des droits de l'homme et ses implications en matière de sanctions administratives, cit., in toto.

71 Así, las sanciones pecuniarias que motivan litigios se tramitan como recursos de plena jurisdicción (p.e., la Sentencia del Consejo de Estado francés de 22 de julio de 1994, Centre hospitalier Gérard-Marchant, req. n. $\left.{ }^{\circ} 118155\right)$. 
